Cochrane Database of Systematic Reviews

\title{
Cannabinoids for the treatment of dementia (Review)
}

Krishnan S, Cairns R, Howard R

Krishnan S, Cairns R, Howard R.

Cannabinoids for the treatment of dementia.

Cochrane Database of Systematic Reviews 2009, Issue 2. Art. No.: CD007204.

DOI: 10.1002/14651858.CD007204.pub2.

www.cochranelibrary.com 
TABLE OF CONTENTS

HEADER 1

ABSTRACT

PLAIN LANGUAGE SUMMARY

BACKGROUND

OBJECTIVES

METHODS

RESULTS

DISCUSSION

AUTHORS' CONCLUSIONS

ACKNOWLEDGEMENTS

REFERENCES

CHARACTERISTICS OF STUDIES

ADDITIONAL TABLES

CONTRIBUTIONS OF AUTHORS

DECLARATIONS OF INTEREST

INDEX TERMS 
[Intervention Review]

\section{Cannabinoids for the treatment of dementia}

Sarada Krishnan ${ }^{1}$, Ruth Cairns ${ }^{2}$, Robert Howard ${ }^{3}$

1Mental Health of Older Adults, Maudsley Hospital, London, UK. 2Department of Psychological Medicine, Institute of Psychiatry, London, UK. 3 Institute of Psychiatry, London, UK

Contact address: Sarada Krishnan, Mental Health of Older Adults, Maudsley Hospital, Denmark Hill, London, SE5 8AZ, UK.

S.Krishnan@iop.kcl.ac.uk, skrishnan@doctors.org.uk.

Editorial group: Cochrane Dementia and Cognitive Improvement Group.

Publication status and date: New, published in Issue 1, 2010.

Citation: Krishnan S, Cairns R, Howard R. Cannabinoids for the treatment of dementia. Cochrane Database of Systematic Reviews 2009, Issue 2. Art. No.: CD007204. DOI: 10.1002/14651858.CD007204.pub2.

Copyright @ 2010 The Cochrane Collaboration. Published by John Wiley \& Sons, Ltd.

\section{A B S T R A C T}

\section{Background}

Following the discovery of an endogenous cannabinoid system and the identification of specific cannabinoid receptors in the central nervous system, much work has been done to investigate the main effects of these compounds. There is increasing evidence that the cannabinoid system may regulate neurodegenerative processes such as excessive glutamate production, oxidative stress and neuroinflammation. Neurodegeneration is a feature common to the various types of dementia and this has led to interest in whether cannabinoids may be clinically useful in the treatment of people with dementia. Recent studies have also shown that cannabinoids may have more specific effects in interrupting the pathological process in Alzheimer's disease.

\section{Objectives}

To determine from available research whether cannabinoids are clinically effective in the treatment of dementia.

\section{Search methods}

The Specialized Register of the Cochrane Dementia and Cognitive Improvement Group (CDCIG), The Cochrane Library, MEDLINE, EMBASE, PsycINFO, CINAHL and LILACS were searched on 11 April 2008 using the terms: cannabis or cannabinoid* or endocannabinoid ${ }^{*}$ or cannabidiol or THC or CBD or dronabinol or delta-9-tetrahydrocannabinol or marijuana or marihuana or hashish. The CDCIG Specialized Register contains records from all major health care databases (The Cochrane Library, MEDLINE, EMBASE, PsycINFO, CINAHL, LILACS) as well as from many clinical trials registries and grey literature sources.

\section{Selection criteria}

All double-blind and single (rater)-blind randomized placebo controlled trials assessing the efficacy of cannabinoids at any dose in the treatment of people with dementia.

\section{Data collection and analysis}

Two reviewers independently examined the retrieved studies for inclusion according to the selection criteria. They then independently assessed the methodological quality of selected trials and extracted data where possible.

\section{Main results}

Only one study met the inclusion criteria. The data in the study report were presented in such a way that they could not be extracted for further analysis and there was insufficient quantitative data to validate the results. 


\section{Authors' conclusions}

This review finds no evidence that cannabinoids are effective in the improvement of disturbed behaviour in dementia or in the treatment of other symptoms of dementia. More randomized double-blind placebo controlled trials are needed to determine whether cannabinoids are clinically effective in the treatment of dementia.

\section{PLAIN LANGUAGE SUMMARY}

No evidence that cannabinoids are effective in the improvement of disturbed behaviour in dementia or in the treatment of other symptoms of dementia

Cannabinoids are compounds derived from the cannabis plant (Cannabis sativa). Laboratory studies have indicated that cannabinoids may regulate some of the processes that lead to neurodegeneration. This suggests that cannabinoids could be useful in the treatment of neurodegenerative dementias such as Alzheimer's disease. So far, only one small randomized controlled trial has assessed the efficacy of cannabinoids in the treatment of dementia. This study had poorly presented results and did not provide sufficient data to draw any useful conclusions. 


\section{B A C K G R O U N D}

\section{Description of the condition}

Dementia is a common chronic condition mainly affecting older adults and characterised by a progressive decline in cognitive and functional ability. Around 750,000 people in the UK currently have dementia and this number is predicted to increase by as much as three-fold over the next 50 years due to the increasing size of the ageing population. This disabling condition brings with it a significant burden to the individual and their carers, as well as a large financial burden (Lowin 2001), both of which are factors driving the need to identify effective therapeutic interventions.

Cholinesterase inhibitor drugs, such as Donepezil, are currently used to treat Alzheimer's dementia and can improve cognitive symptoms, activities of daily living and behaviour. However, treatment effects are small and they only act to delay an inevitable decline by around 9 to 12 months (Birks 2006). At least half of patients with dementia will also experience behavioural and psychological symptoms (BPSD) such as agitation, aggression and psychosis. These symptoms lead to significant caregiver stress (Rabins 1982), are distressing for the patient, and often precipitate placement in residential or nursing homes (Steele 1990). Antipsychotic drugs are widely used to treat BPSD but have only modest efficacy (Ballard 2006; Schneider 2006). Use of these drugs in dementia is also associated with serious side effects including an increased risk of cerebrovascular adverse events and death (FDA 2005; MHRA 2004; Schneider 2005). It has been shown recently that the cholinesterase inhibitor Donepezil has little benefit in the management of BPSD (Howard 2007). Accordingly there is a need for new, safe and more effective treatments for dementia and its associated symptoms.

\section{Description of the intervention}

The cannabinoids are one potential agent under investigation for the treatment of dementia. These compounds are the active components derived from the cannabis plant (Cannabis sativa). The first cannabinoids to be identified were the main psychoactive compound delta-9-tetrahydrocannabinol (THC) and the nonpsychoactive compound cannabidiol (CBD), although there are thought to be numerous other cannabinoids, some of which may modulate the response to THC (Iversen 2000). An endogenous cannabinoid system has been identified where these compounds exert their effect by acting at two specific cannabinoid receptors, CB1 and CB2 (Howlett 2002; Matsuda 1990). CB1 receptors are found throughout the central nervous system, particularly in the hippocampus, basal ganglia and cerebellum. In contrast CB2 receptors are expressed in peripheral tissues, especially on white blood cells, and are much less widespread in the central nervous system (see Campbell 2007 for a review). Some recent studies have identified CB2 receptors on brainstem neurons (Van Sickle 2005) and cerebellar neurons (Onaivi 2006) but their role is not yet understood.

\section{How the intervention might work}

Several neurobiological effects of cannabinoids have been demonstrated which could be relevant in the treatment of dementia. The main function of the endogenous cannabinoid system is thought to be the regulation of synaptic transmission (Baker 2003) and this process can be disordered in many neurological conditions including dementia. Studies are also beginning to provide evidence of the neuroprotective effects of cannabinoids. CB1 receptors have been shown to regulate processes such as excessive glutamate production and subsequent oxidative stress, which can damage neurons and lead to neurodegeneration (Grundy 2002). In vitro experiments have demonstrated that cannabinoids can protect neurons from this type of excitotoxic damage (Hampson 1998; Shen 1998) and from hypoxic damage (Nagayama 1999). There is also some evidence that $\mathrm{CB} 2$ receptors may be involved in neuroprotection by reducing neuroinflammation (Ehrhart 2005). Neurodegeneration is a feature common to the various types of dementia and the neuroprotective effects of cannabinoids may therefore be beneficial in slowing the progression of these diseases.

Cannabinoids may have more specific effects in Alzheimer's disease pathology. A recent study has shown that THC diminishes acetylcholinesterase-induced amyloid beta-peptide aggregation, the key pathological marker of Alzheimer's disease (Eubanks 2006). The same research group report that THC competitively inhibits the enzyme acetylcholinesterase (AChE) - a similar action to the anti-dementia drugs like Donepezil. Another study investigated the effects of cannabinoids in rats injected with amyloid betapeptide to model Alzheimer's disease. Intracerebroventricular administration of a synthetic cannabinoid (WIN55,212-2) to these rats led to a prevention of their cognitive deficit and decreased neurotoxicity (Ramirez 2005). These studies suggest that cannabinoids could interrupt the disease process as well as treat symptoms in Alzheimer's disease.

\section{Why it is important to do this review}

There have been some clinical studies examining the effects of cannabinoids on symptom management in dementia. A small open-label pilot study showed that daily administration of dronabinol (synthetic THC) reduced night-time motor activity and agitation in patients with dementia (Walther 2006). Volicer 1997 showed that dronabinol improved weight gain in a small group of patients with Alzheimer's disease who were refusing food when compared with placebo. Preliminary data also suggest that cannabidiol may be an effective hypnotic (Grinspoon 1993).

\section{O B JECTIVES}

To determine from available research whether cannabinoids are clinically effective in the treatment of dementia.

\section{METHODS}

\section{Criteria for considering studies for this review}

\section{Types of studies}

All double-blind and single (rater)-blind randomized placebo controlled trials assessing the efficacy of cannabinoids in the treatment of dementia were considered.

\section{Types of participants}

People of any age and either sex diagnosed with Alzheimer's dementia, vascular dementia, mixed dementia or unspecified dementia of any severity and from any setting were included. The diagnosis should be made using internationally recognised criteria including DSM (APA 1994), ICD (WHO 1993) or NINCDSADRDA (National Institute of Neurological and Communicative 
Disorders and Stroke - Alzheimer's Disease and Related Disorders Association) (McKhann 1984).

\section{Types of interventions}

The administration of cannabinoids by any route, at any dose, for any duration.

\section{Types of outcome measures}

\section{Primary outcomes}

- Clinical global impression of change

- Cognitive function

\section{Secondary outcomes}

- Behavioural symptoms including agitation and night-time motor activity

- Mood including biological symptoms (e.g. sleep, appetite)

- Functional performance

- Activities of daily living

- Caregiver burden and caregiver quality of life

- Quality of life

- Acceptability and adverse effects

- Institutionalisation

- Costs of health and social care

- Mortality

\section{Search methods for identification of studies}

See: Cochrane Dementia and Cognitive Improvement Group methods used in reviews.

The Specialized Register of the Cochrane Dementia and Cognitive Improvement Group (CDCIG) was searched on 11 April 2008 for all years up to December 2005. This register contains records from the following major healthcare databases The Cochrane Library, MEDLINE, EMBASE, PsycINFO, CINAHL and LILACS, and many ongoing trial databases and other grey literature sources. The following search terms were used: cannabis or cannabinoid or endocannabinoid or marijuana or hashish

The Cochrane Library, MEDLINE, EMBASE, PsycINFO, CINAHL and LILACS were searched separately on 11 April 2008 for records added to these databases after December 2005 to April 2008. The search terms used to identify relevant controlled trials on dementia, Alzheimer's disease and mild cognitive impairment for the Group's Specialized Register can be found in the Group's module on The Cochrane Library. These search terms were combined with the following search terms and adapted for each database, where appropriate: cannabis or cannabinoid ${ }^{*}$ or endocannabinoid ${ }^{*}$ or cannabidiol or THC or CBD or dronabinol or delta-9-tetrahydrocannabinol or marijuana or marihuana or hashish

On 11 April 2008 the Specialized Register consisted of records from the following databases:

\section{Healthcare databases}

- The Cochrane Library: (2006, Issue 1);

- MEDLINE (1966 to 2006/07, week 5);

- EMBASE (1980 to 2006/07);
- PsycINFO (1887 to 2006/08, week 1);

- CINAHL (1982 to 2006/06);

- SIGLE (Grey Literature in Europe) (1980 to 2005/03);

- LILACS: Latin American and Caribbean Health Science Literature (http://bases.bireme.br/cgi-bin/wxislind.exe/iah/ online/?IsisScript=iah/iah.xis\&base=LILACS\&lang=i\&form=F) (last searched 29 August 2006).

\section{Conference proceedings}

- ISTP (http://portal.isiknowledge.com/portal.cgi) (Index to Scientific and Technical Proceedings) (to 29 August 2006);

- INSIDE (BL database of Conference Proceedings and Journals) (to June 2000);

\section{Theses}

- Index to Theses (formerly ASLIB) (http://www.theses.com/) (UK and Ireland theses) (1716 to 11 August 2006);

- Australian Digital Theses Program (http://adt.caul.edu.au/): (last update 24 March 2006);

- Canadian Theses and Dissertations (http:// www.collectionscanada.ca/thesescanada/index-e.html): 1989 to 28 August 2006);

- DATAD - Database of African Theses and Dissertations (http:// www.aau.org/datad/backgrd.htm);

- Dissertation Abstract Online (USA) (http://wwwlib.umi.com/ dissertations/gateway) (1861 to 28 August 2006).

\section{Ongoing trials}

UK

- National Research Register (http://www.update-software.com/ projects/nrr/) (last searched issue 3/2006);

- ReFeR (http://www.refer.nhs.uk/ViewWebPage.asp? Page=Home) (last searched 30 August 2006);

- Current Controlled trials: Meta Register of Controlled trials (mRCT) (http://www.controlled-trials.com/) (last searched 30 August 2006) :

- ISRCTN Register - trials registered with a unique identifier

- Action medical research

- Kings College London

- Laxdale Ltd

- Medical Research Council (UK)

- NHS Trusts Clinical Trials Register

- National Health Service Research and Development Health Technology Assessment Programme (HTA)

- National Health Service Research and Development Programme 'Time-Limited' National Programmes

- National Health Service Research and Development Regional Programmes

- The Wellcome Trust

- Stroke Trials Registry (http://www.strokecenter.org/trials/ index.aspx) (last searched 31 August 2006);

\section{Netherlands}

- Nederlands Trial Register (http://www.trialregister.nl/trialreg/ index.asp) (last searched 31 August 2006); 


\section{USA/International}

- ClinicalTrials.gov (http://www.ClinicalTrials.gov) (last searched 31 August 2006) (contains all records from http:// clinicalstudies.info.nih.gov/);

- IPFMA Clinical trials Register: www.ifpma.org/clinicaltrials.html. The Ongoing Trials database within this Register searches http://www.controlled-trials.com/isrctn, http:// www.ClinicalTrials.gov and http://www.centerwatch.com/. The ISRCTN register and Clinicaltrials.gov are searched separately. Centerwatch is very difficult to search for our purposes and no update searches have been done since 2003.

- The IFPMA Trial Results databases searches a wide variety of sources among which are:

- http://www.astrazenecaclinicaltrials.com (seroquel, statins)

- http://www.centerwatch.com

- http://www.clinicalstudyresults.org

- http://clinicaltrials.gov

- http://www.controlled-trials.com

- http://ctr.gsk.co.uk

- http://www.lillytrials.com (zyprexa)

- http://www.roche-trials.com (anti-abeta antibody)

- http://www.organon.com

- http://www.novartisclinicaltrials.com (rivastigmine)

- http://www.bayerhealthcare.com

- http://trials.boehringer-ingelheim.com

- http://www.cmrinteract.com

- http://www.esteve.es

- http://www.clinicaltrials.jp

This part of the IPFMA database is searched and was last updated on 4 September 2006;

- Lundbeck Clinical Trial Registry (http:// www.lundbecktrials.com) (last searched 15 August 2006);

- Forest Clinical trial Registry (http:// www.forestclinicaltrials.com/) (last searched 15 August 2006).

The search strategies used to identify relevant records in MEDLINE, EMBASE, PsycINFO, CINAHL and LILACS can be found in the Group's module on The Cochrane Library.

We also searched a number of other resources including the Google search engine and the Norml website http://www.norml.org/ index.cfm to identify other relevant references (for a complete list of sources searched and search strategies used see additional Table $1)$.

In addition, we contacted the first authors of two relevant trials to request details of any unpublished or current studies that might meet the inclusion criteria for this review. The reference lists of retrieved articles were also examined to look for additional trials for inclusion.

\section{Data collection and analysis}

\section{Selection of studies}

The search citations were examined by a single reviewer (SK) and any irrelevant studies were discarded on the basis of their abstracts. Studies which could possibly be relevant were retrieved for further assessment. Two reviewers (SK, RC) then examined these studies independently and considered them for inclusion according to pre-determined eligibility criteria. Disagreements were resolved by discussion and there were no unresolved differences.

\section{Quality assessment}

The same two reviewers (SK, RC) independently assessed the methodological quality of each selected trial, with reference to the Cochrane Collaboration guidelines. Particular consideration was given to the randomization process, allocation concealment, blinding and reporting of dropouts in order to assess the internal validity of the studies. For the domain of allocation concealment, a simple grading system was used:

Category A (adequate) is where the report describes allocation of treatment by: (i) some form of centralized randomized scheme, such as having to provide details of an enrolled participant to an office by phone to receive the treatment group allocation; (ii) some form of randomization scheme controlled by a pharmacy; (iii) numbered or coded containers, such as in a pharmaceutical trial in which capsules from identical-looking numbered bottles are administered sequentially to enrolled participants; (iv) an on-site or coded computer system, given that the allocations were in a locked, unreadable file that could be accessed only after inputting the characteristics of an enrolled participant; or (v) if assignment envelopes were used, the report should at least specify that they were sequentially numbered, sealed, opaque envelopes; (vi) other combinations of described elements of the process that provides assurance of adequate concealment.

Category B (unclear) is where the report describes allocation of treatment by: (i) use of a "list" or "table" to allocate assignments; (ii) use of "envelopes" or "sealed envelopes"; (iii) stating the study is "randomized" without further detail.

Category C (inadequate) is where the report describes allocation of treatment by: (i) alternation; (ii) reference to case record numbers, dates of birth, day of week, or any such approach; (iii) any allocation procedure that is entirely transparent before assignment, such as an open list of random numbers or assignments.

Studies with inadequate allocation concealment (Category C) were excluded as this has been shown to be associated with bias (Chalmers 1983, Schulz 1995).

\section{Data extraction}

Data on participants (including ethnicity, age of onset and previous drug treatment), methods, interventions, outcomes and results was extracted independently by two reviewers (SK, RC) using a data extraction form.

Attempts were made to identify data for each outcome measure on every patient randomized. To allow an intention-to-treat analysis, the data were sought irrespective of compliance, whether or not the person was subsequently deemed ineligible, or otherwise excluded from treatment or follow-up. Where intention-to-treat data were not available, an analysis of participants who completed the trial was done.

For binary data (e.g. mortality, numbers experiencing adverse effects), the number in each treatment group and the number experiencing the outcome of interest were sought. In some cases 
it may be necessary, due to variation in the way response to treatment is measured, to record outcomes as "clinical improvement" versus "no clinical improvement", regardless of the scales used by the authors. For continuous data the mean change from baseline, the standard error of the mean change and the number of patients were extracted for each treatment group at each assessment for each of the outcomes where available. Where changes from baseline were not reported, the mean, standard deviation and number of patients for each treatment group at each point in time were extracted if available. The baseline assessment is defined as the latest available assessment prior to randomization but no longer than two months before this time.

Where studies of a crossover design met the inclusion criteria, only data from the first treatment period were considered eligible for inclusion in order to avoid the effects of carry-over and because participants with a degenerative dementia are likely to deteriorate over time.

Only data published in numerical form in tables were utilised in this review.

\section{Data analysis}

Missing data and drop-out rates will be assessed for each of the included studies. The number of participants who are included in the final analysis will be reported as a proportion of all participants in the study.

For binary outcomes, such as clinical improvement or no clinical improvement, the numbers in each treatment group and the numbers experiencing outcomes of interest will be sought. The odds ratio will be used to measure treatment effect with a $95 \%$ confidence interval.

Where continuous scales of measurement are used to assess the effects of treatment, the summary statistics required for each trial and each outcome are the mean change from baseline, the standard error of the mean change and the number of patients for each treatment group at each assessment. Where changes from baseline are not reported, the mean, standard deviation and the number of patients for each treatment group at each assessment time will be extracted if possible.

If there are sufficient data, and it is appropriate to do so, a metaanalysis will be conducted. Meta-analysis requires the combination of data from the trials that may not use the same rating scale to assess an outcome. Binary data will be pooled and the odds ratio will be used to calculate a weighted estimate of the typical treatment effect across trials. The measure of the treatment difference for any continuous outcome will be the weighted mean difference when the trials use the same scale and the standardised mean difference (the absolute mean difference divided by the standard deviation) when they use different scales.

A weighted estimate of the typical treatment effect across trials will be calculated and an overall estimate of the treatment difference will be presented. In all cases the overall estimate from a fixed effects model will be presented and a test for heterogeneity will be performed. If, however, there is evidence of heterogeneity then either only homogenous results will be pooled, or a randomeffects model will be used (which would result in wider confidence intervals than in a fixed-effects model).
If the duration of included trials varies too much to combine the trials into one meta-analysis, then the data will be divided into smaller time periods and a separate meta-analysis will be performed for each period.

\section{RES U L T S}

\section{Description of studies}

See: Characteristics of included studies; Characteristics of excluded studies

\section{Results of the search}

The database searches resulted in two trials being identified as potentially meeting the inclusion criteria (Walther 2006, Volicer 1997). Paper copies of the reports were obtained and independently assessed for inclusion by SK and RC. Only one of these was included in the review.

\section{Included studies}

The one trial included in the review (Volicer 1997) was a placebo-controlled crossover design that examined the effects of dronabinol (synthetic THC) on anorexia and disturbed behaviour in patients with Alzheimer's disease. The participants were 15 patients hospitalised in a specialist unit with a diagnosis of probable Alzheimer's disease, according to DSM-III-R and NINCDS-ADRDA criteria, who were refusing food. Participants were randomly assigned to two groups to receive either dronabinol (2.5 mg twice daily) or placebo for six weeks before there was a crossover of treatment for a further six weeks. There was no washout period. Baseline measurements were taken the week prior to randomization and then at weekly intervals during the study. Outcomes assessed were:

(1) Nutritional status as assessed by body weight and triceps skin fold thickness. Plasma albumin and lymphocyte count were also measured at the beginning and end of each treatment period.

(2) Disturbed behaviour as measured by Cohen-Mansfield Agitation Inventory (CMAI) (Cohen-Mansfield 1989).

(3) Affect as measured by the Lawton Observed Affect Scale - Past (Lawton 1996).

Eleven out of 12 patients were on psychoactive medication before the study started but this did not change during the study period and the authors report that no new antidepressants were initiated less than four weeks before the start of the study.

It is questionable whether this study met the quality requirements for inclusion because the study report contained insufficient detail regarding the randomization process, allocation concealment and blinding, and the reporting of dropouts was incomplete (see: Risk of bias in included studies). However, it was the only double-blind randomized placebo-controlled study identified that addressed the clinical effectiveness of cannabinoids in the treatment of dementia, so both reviewers felt it should be included. The author was contacted for further information/data for analysis but we were informed that there is no longer any primary data and that it was discarded some time ago. 


\section{Excluded studies}

Walther 2006 was excluded because it was an open-label pilot study examining the effect of dronabinol on nighttime agitation in severe dementia.

\section{Risk of bias in included studies}

Selection bias - the report states that "subjects were randomly assigned" to the treatment groups but the randomization process was not described and it was not clear if concealment of allocation was performed.

Performance bias - the study is described as "double-blind" but it is not stated whether caregivers as well as outcome assessors were blinded to treatment given. The caregivers knew the study objectives which may have biased their ratings of participants' behaviour. The participants were mostly suffering from severe dementia so any incomplete blinding of this group is less likely to be a source of bias.

Attrition bias - 4/15 participants did not complete the study. Of these, three were withdrawn and omitted from the analysis and one died during the study but was included in the analysis using estimated values based on his previous measures.

Detection bias - there was no information on how and by whom the assessments and analysis were carried out.

Other sources of bias - the study had no wash-out period. There may be a carry-over effect of the dronabinol treatment as its metabolites have been shown to be detectable in urine several weeks after ingestion. This could lead to an underestimation of the overall treatment effect. The study was also supported by a pharmaceutical company which could lead to reporting bias.

\section{Effects of interventions}

The data reported in the Volicer 1997 study were presented in such a way that it was not possible to extract them for analysis. There was no baseline comparison of the two treatment groups (dronabinol first and placebo first) and the data regarding many of the outcomes were not reported in sufficient detail to enter into further analysis. The number of participants whose data were analysed was also small $(n=12)$.

The results as reported by the original authors are described below. First treatment period data will be reported where possible in order to avoid the effects of carry-over.

\section{Dronabinol versus placebo: body weight}

Body weight and triceps skin fold thickness were reported to increase during the 12 week study period regardless of the order of treatment. In the first treatment period participants on dronabinol gained $7.0 \pm 1.5 \mathrm{lb}$ and those on placebo gained $4.6 \pm 1.3 \mathrm{lb}$. Caloric intake did not change during the study period and was similar in both treatment periods.

\section{Dronabinol versus placebo: disturbed behaviour}

Disturbed behaviour as measured by the CMAI was reported to decrease during both dronabinol treatment periods and this decrease persisted during the placebo period following dronabinol treatment.

\section{Dronabinol versus placebo: affect}

Negative affect scores were reported to decrease during the 12 week study period in both groups, more so when participants were taking dronabinol rather than placebo. Positive affect was found to remain similar throughout all treatment periods.

No further detail can be given because of insufficient quantitative data.

\section{Adverse effects}

The study authors report that there were no serious adverse effects although one patient suffered a grand mal seizure following the first dose of dronabinol. It was not clear whether this was more likely to be due to advanced dementia or the dronabinol. The data on adverse reactions were not clearly presented by treatment period but overall more patients suffered from tiredness, somnolence and euphoria when comparing dronabinol treatment and placebo. No statistical tests were reported to compare these two groups.

\section{DISCUSSION}

This review aimed to evaluate whether cannabinoids are clinically effective in the treatment of dementia with particular interest in outcomes of cognitive function and global improvement. Only one small study (Volicer 1997) has been included which was designed to focus on the effects of the cannabinoid dronabinol on anorexia in Alzheimer's disease. Whilst improvement of anorexia is clearly an important outcome for patients and their carers, it was not a primary outcome of interest in this review. Volicer 1997 concluded that the cannabinoid dronabinol may be useful in the treatment of anorexia and to improve disturbed behaviour in people with Alzheimer's disease. However the lack of quantitative data and the unclear risk of bias in key domains of this study means that no useful conclusions can be drawn in this review.

This review has also found that there are no other randomized placebo-controlled trials examining the effectiveness of cannabinoids in the treatment of dementia which signals a need for further studies in this area.

\section{AUTHORS' CONCLUSIONS}

\section{Implications for practice}

At present this review finds no evidence that cannabinoids are effective in the improvement of disturbed behaviour in dementia or in the treatment of other symptoms of dementia.

\section{Implications for research}

There is growing neurobiological evidence that cannabinoids may be useful in modulating disease processes in dementia but despite this there are almost no clinical studies in this area. There is a need for more randomized double-blind placebo-controlled trials to determine whether cannabinoids are clinically effective in the treatment of dementia.

\section{ACKNOWLEDGEMENTS}

The support of the Cochrane Dementia and Cognitive Improvement Group and in particular the advice of Helen Collins is gratefully acknowledged. We also thank Ann Fonfa for her contributions as our consumer editor. 


\section{RE F E R E N C E S}

\section{References to studies included in this review}

Volicer 1997 \{published data only\}

Volicer L, Stelly M, Morris J, McLaughlin J, Volicer BJ. Effects of dronabinol on anorexia and disturbed behaviour in patients with Alzheimer's Disease.. International Journal of Geriatric Psychiatry 1997;12:913-919.

\section{References to studies excluded from this review}

Walther 2006 \{published data only\}

Walther S, Mahlberg R, Eichmann U, Kunz D. Delta-9tetrahydrocannabinol for nighttime agitation in severe dementia.. Psychopharmacology 2006;185:524-528.

\section{References to ongoing studies}

Walther 2007 \{unpublished data only\}

Walther S. Placebo-controlled, randomised, double blind crossover trial on dronabinol, a cannabinoid-1-receptor agonist, for behavioral and circadian rhythm disturbances in dementia. Registration-number 2007DR2217 (Swissmedic trial registry).

\section{Additional references}

\section{APA 1994}

American Psychiatric Association. Diagnostic and Statistical Manual of Mental Disorders. 4th Edition. Washington DC: American Psychiatric Press, 1994.

\section{Baker 2003}

Baker D, Pryce G, Giovannoni G, Thompson AJ. The therapeutic potential of cannabis. The Lancet Neurology 2003;2:291-8.

\section{Ballard 2006}

Ballard C, Waite J, Birks J. Atypical antipsychotics for aggression and psychosis in Alzheimer's disease. Cochrane Database of Systematic Reviews 2006, Issue 1. [DOI: 10.1002/14651858.CD003476.pub2]

\section{Birks 2006}

Birks J. Cholinesterase inhibitors for Alzheimer's disease. Cochrane Database of Systematic Reviews 2006, Issue 1. [DOI: 10.1002/14651858.CD005593]

\section{Campbell 2007}

Campbell VA, Gowran A. Alzheimer's disease; taking the edge off with cannabinoids?. British Journal of Pharmacology 2007;152:655-662.

\section{Chalmers 1983}

Chalmers TC, Celano P, Sacks HS, Smith H Jr. Bias in treatment assignment in controlled clinical trials. New England Journal of Medicine 1983;309:1358-61.

\section{Cohen-Mansfield 1989}

Cohen-Mansfield J, Marx MS, Rosenthal AS. A description of agitation in a nursing home. Journal of Gerontology 1989;44:M77-M84.

Ehrhart 2005

Ehrhart J, Obergon D, Mori T, Hou H, Sun N, Bai Y, Klein T, Fernandez F, Tan J, Shytle RD. Stimulation of CB2 suppresses microglial activation. Journal of Neuroinflammation 2005;2:29.

\section{Eubanks 2006}

Eubanks LM, Rogers CJ, Beuscher AE 4th, Koob GF, Olson AJ, Dickerson TJ, et al. A molecular link between the active component of marijuana and Alzheimer's disease pathology. Molecular Pharmaceutics 2006;3:773-7.

\section{FDA 2005}

Centre for Drug Evaluation and Research. FDA public health advisory: deaths with antipsychotics in elderly patients with behavioural disturbances. FDA April 2005.

\section{Grinspoon 1993}

Grinspoon L, Bakalar JB. Marihuana, the forbidden medicine. New Haven, CT: Yale University Press, 1993.

\section{Grundy 2002}

Grundy RI. The therapeutic potential of the cannabinoids in neuroprotection. Expert Opinion on Investigational Drugs 2002;11:1365-74.

\section{Hampson 1998}

Hampson AJ, Grimaldi M, Axelrod J, Wink D. Cannabidiol and delta-9-tetrahydrocannabinol are neuroprotective antioxidants. Proceedings of the National Academy of Sciences 1998;95:8268-73

\section{Howard 2007}

Howard RJ, Juszczak E, Ballard CG, Bentham P, Brown RG, Bullock R, et al. Donepezil for the treatment of agitation in Alzheimer's disease. New England Journal of Medicine 2007;357:1382-92.

\section{Howlett 2002}

Howlett AC, Barth F, Bonner T, Cabral G, Casellas P, Devane WA et al. International Union of Pharmacology XXVII. Classification of cannabinoid receptors. Pharmacological Reviews 2002;54:161-202.

\section{Iversen 2000}

Iversen LL. The science of marijuana. Oxford: Oxford University Press, 2000

Lawton 1996

Lawton MP, Van Haitsma K, Klapper J. Observed affect in nursing home residents with Alzheimer's disease. Journals of Gerontology. Series B, Psychological sciences and social sciences 1996;51B:P3-P14. 


\section{Lowin 2001}

Lowin A, Knapp M, McCrone P. Alzheimer's disease in the UK: comparative evidence on cost of illness and volume of health services research funding. International Journal of Geriatric Psychiatry 2001;16:1143-8.

\section{Matsuda 1990}

Matsuda LA, Lolait SJ, Brownstein MJ, Young AC, Bonner T. Structure of a cannabinoid receptor and functional expression of the cloned cDNA. Nature 1990;346:561-4.

\section{McKhann 1984}

McKhann G, Drachman D, Folstein M, Katzman R, Price D, Stadlan EM. Clinical diagnosis of Alzheimer's Disease: Report of the NINCDS-ADRDA Work Group under the auspices of Department of Health and Human Services Task Force on Alzheimer's Disease. Neurology 1984;34:939-44.

\section{MHRA 2004}

Medicines and Healthcare Products Regulatory Agency. New advice issued on risperidone and olanzepine. MHRA March 2004.

\section{Nagayama 1999}

Nagayama T, Sinor AD, Simon RP, Chen J, Graham SH, Jin K, et al. Cannabinoids and neuroprotection in global and focal cerebral ischaemia and in neuronal cultures. Journal of Neuroscience 1999;19:2987-95.

\section{Onaivi 2006}

Onaivi ES. Neuropsychological evidence for the functional presence and expression of cannabinoid CB2 receptors in the brain. Neuropsychobiology 2006;54:231-246.

\section{Rabins 1982}

Rabins PV, Mace NL, Lucas MJ. The impact of dementia on the family. Journal of the American Medical Society 1982;248:333-5.

\section{Ramirez 2005}

Ramirez BG, Blazquez C, Gomez del Pulgar T, Guzman M, de Ceballos M. Prevention of Alzheimer's disease pathology by cannabinoids: neuroprotection mediated by blockade of microglial activation. The Journal of Neuroscience 2005;25:1904-13.

\section{Schneider 2005}

Schneider LS, Dagerman KS, Insel P. Risk of death with atypical antipsychotic drug treatment for dementia: meta-analysis of

\section{CHARACTERISTICS OF STUDIES}

Characteristics of included studies [ordered by study ID] randomized placebo-controlled trials. Journal of the American Medical Association 2005;294:1934-43.

\section{Schneider 2006}

Schneider LS, Dagerman KS, Insel P. Efficacy and adverse effects of atypical antipsychotics for dementia: meta-analysis of randomized placebo-controlled trials. American Journal of Geriatric Psychiatry 2006;14:191-210.

\section{Schulz 1995}

Schulz KF, Chalmers I, Hayes RJ, Altman DG. Empirical evidence of bias: dimensions of methodological quality associated with estimates of treatment effects in controlled trials. JAMA 1995;273:408-12.

\section{Shen 1998}

Shen M, Thayer SA. Cannabinoid receptor agonists protect cultured rat hippocampal neurons from excitotoxicity. Molecular Pharmacology 1998;54:459-62.

\section{Steele 1990}

Steele C, Rovner B, Chase GA, Folstein M. Psychiatric symptoms and nursing home placement of patients with Alzheimer's disease. American Journal of Psychiatry 1990;147:1049-51.

\section{Van Sickle 2005}

Van Sickle MD, Duncan M, Kingsley PJ, Mouihate A, Urbani P, Mackie K, et al. Identification and functional characterization of brainstem cannabinoid CB2 receptors. Science 2005;310:329-332.

\section{Volicer 1997}

Volicer L, Stelly M, Morris J, McLaughlin J, Volicer BJ. Effects of dronabinol on anorexia and disturbed behaviour in patients with Alzheimer's disease. International Journal of Geriatric Psychiatry 1997;12:913-9.

\section{Walther 2006}

Walther S, Mahlberg R, Eichmann U, Kunz D. Delta-9tetrahydrocannabinol for nighttime agitation in severe dementia. Psychopharmacology 2006;185:524-8.

\section{WHO 1993}

World Health Organisation. The ICD-10 Classification of Mental and Behavioural Disorders: Diagnostic Criteria for Research. Geneva: World Health Organisation, 1993.

Volicer 1997

Methods Randomised double blind placebo-controlled cross-over trial (randomization method not given)

$\begin{array}{ll}\text { Participants } & \text { Country: USA } \\ & \text { Single centre }\end{array}$


Volicer 1997 (Continued)

Subjects: 15 patients hospitalised in a Dementia Study Unit

Selection criteria: diagnosis of probable Alzheimer's dementia with simple food refusal, normal blood tests or no significant laboratory abnormalities

Exclusion criteria: problems with choking on food and liquids, hypersensitivity to dronabinol or sesame oil.

Age range: 65-82 years, 11 male, 1 female (information only given for 12 patients)

\begin{tabular}{ll} 
Interventions & $\begin{array}{l}\text { Placebo or Dronabinol } 2.5 \mathrm{mg} \text { capsule twice daily for } 6 \text { weeks followed by switch } \\
\text { treatment for a further } 6 \text { weeks }\end{array}$ \\
\hline Outcomes & Weight gain, body mass index (BMI), triceps skin fold thickness, caloric intake \\
& Disturbed behaviour (Cohen-Mansfield Agitation Inventory score) \\
Affect (Lawton Observed Affect Scale - Past) \\
Plasma albumin and lymphocyte count
\end{tabular}

Notes Small study group. Short duration of treatment. Almost all participants in the analysis were male.

\section{Risk of bias}

\begin{tabular}{lll}
\hline Bias & Authors' judgement & Support for judgement \\
\hline $\begin{array}{ll}\text { Adequate sequence gener- } \\
\text { ation? }\end{array}$ & Unclear risk & $\begin{array}{l}\text { Quote: "subjects were randomly assigned to placebo first or dronabinol first } \\
\text { groups". }\end{array}$ \\
& & Comment: No further information provided. \\
\hline
\end{tabular}

\begin{tabular}{ll}
\hline Allocation concealment? & Unclear risk \\
& Comment: No information provided.
\end{tabular}

\begin{tabular}{|c|c|c|}
\hline $\begin{array}{l}\text { Blinding? } \\
\text { Caregiver-reported out- } \\
\text { comes }\end{array}$ & Unclear risk & $\begin{array}{l}\text { Quote: "the study used a double-blind...design"; "Although the study was dou- } \\
\text { ble-blind, the staff knew the objectives of the study." } \\
\text { Comment: Measurement of disturbed behaviour was based on caregiver inter- } \\
\text { views but it was not specifically stated that both caregivers and outcome as- } \\
\text { sessors were blinded. }\end{array}$ \\
\hline $\begin{array}{l}\text { Blinding? } \\
\text { Body weight }\end{array}$ & Low risk & $\begin{array}{l}\text { Quote: "the study used a double-blind...design" } \\
\text { Comment: Probably done if measured by outcome assessors. }\end{array}$ \\
\hline $\begin{array}{l}\text { Incomplete outcome data } \\
\text { addressed? } \\
\text { All outcomes }\end{array}$ & High risk & $\begin{array}{l}4 / 15 \text { participants did not complete the study; three of these were omitted from } \\
\text { the analysis. }\end{array}$ \\
\hline $\begin{array}{l}\text { Free of selective report- } \\
\text { ing? }\end{array}$ & Low risk & $\begin{array}{l}\text { All outcomes were reported on although there was a lack of quantitative data } \\
\text { overall. }\end{array}$ \\
\hline Free of other bias? & High risk & $\begin{array}{l}\text { No wash-out period leading to risk of carry-over effect. Pharmaceutical com- } \\
\text { pany support could lead to reporting bias. }\end{array}$ \\
\hline
\end{tabular}

\section{Characteristics of excluded studies [ordered by study ID]}




\section{\begin{tabular}{ll} 
Study Reason for exclusion \\
\hline
\end{tabular}}

Walther 2006

Not an RCT. Open-label pilot study.

Characteristics of ongoing studies [ordered by study ID]

Walther 2007

\section{Trial name or title \\ Trialname or title}

\begin{tabular}{ll}
\hline Methods & Placebo-controlled, randomised, double blind crossover trial \\
\hline Participants & $\begin{array}{l}\text { Patients }>65 \text { years with Alzheimer dementia or mixed dementia presenting with circadian rhythm } \\
\text { disturbances or behavioral disturbances }\end{array}$ \\
\hline Interventions & dronabinol $2.5 \mathrm{mg}$ at 7 p.m. for two weeks and placebo \\
\hline Outcomes & Night-time motor activity as measured by actigraphy and the neuropsychiatric inventory \\
\hline Starting date & November 2007 \\
\hline Contact information & $\begin{array}{l}\text { Dr. Sebastian Walther, University Hospital of Psychiatry, Bern, Switzerland, Email: walther@puk.u- } \\
\text { nibe.ch }\end{array}$ \\
\hline
\end{tabular}

Notes

\section{ADDITIONAL TABLES}

\section{Table 1. Search strategies and hits returned}

Electronic data- $\quad$ Search strategy
base, trial reg-
ister or website
searched

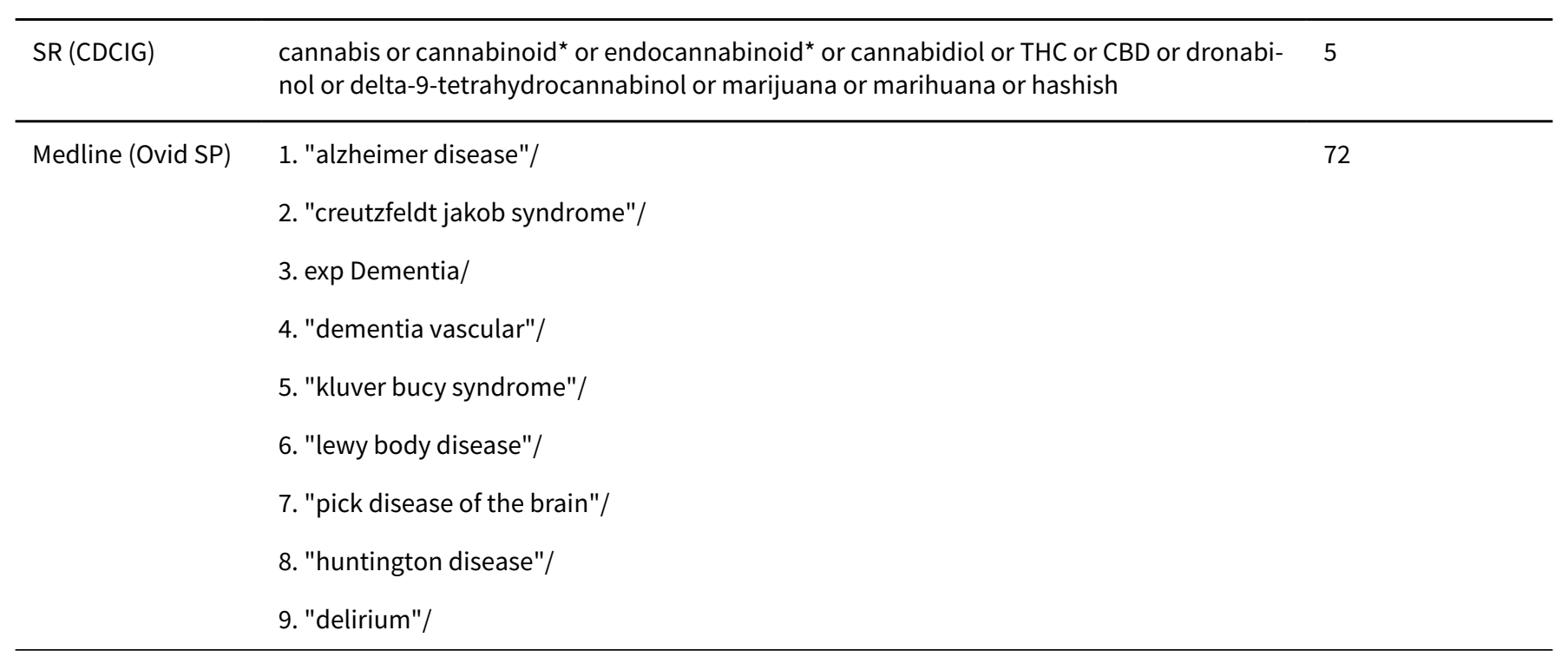


Table 1. Search strategies and hits returned (Continued)

10. "wernicke encephalopathy"/

11. 1 or 2 or 3 or 4 or 5 or 6 or 7 or 8 or 9 or 10

12. (dement ${ }^{\star}$ or neuroprotect* $\left.{ }^{\star}\right) \cdot \mathrm{mp}$.

13. alzheimer ${ }^{\star} \cdot \mathrm{mp}$.

14. (lewy ${ }^{\star}$ and bod $\left.{ }^{\star}\right) \cdot \mathrm{mp}$. [mp=title, original title, abstract, name of substance word, subject heading word]

15. deliri ${ }^{\star} . \mathrm{mp}$.

16. ((cognit* or memory $^{\star}$ or mental $\left.{ }^{\star}\right)$ and $\left(\right.$ declin $^{\star}$ or impair $^{\star}$ or los ${ }^{\star}$ or deteriorat $\left.\left.{ }^{\star}\right)\right) . m p$.

17. (chronic and cerebrovascular).mp.

18. ("organic brain syndrome" or "organic brain disease").mp.

19. "supra nuclear palsy".mp.

20. ("normal pressure hydrocephalus" and shunt*).mp.

21. "benign senescent forgetfulness".mp.

22. (cerebr ${ }^{\star}$ and deteriorat $\left.{ }^{\star}\right)$.mp.

23. (cerebr ${ }^{\star}$ and insufficien $\left.{ }^{\star}\right) \cdot \mathrm{mp}$.

24. (confusion* or confused).mp.

25. (Pick* and disease).mp.

26. (creutzfeldt or JCD or CJD).mp.

27. Huntington ${ }^{\star} . \mathrm{mp}$.

28. Binswanger*.mp.

29. korsako*.mp.

30. "korsakoff syndrome"/

31. (Wernicke ${ }^{\star}$ and (syndrome or encephalopathy)).mp.

32. 12 or 13 or 14 or 15 or 16 or 17 or 18 or 19 or 20 or 21 or 22 or 23 or 24 or 25 or 26 or 27 or 28 or 29 or 30 or 31

33. (cannabis or cannabinoid* or endocannabinoid* or cannabidiol or marihuana or dronabinol or thc or cbd or marijuana or hashish).mp.

34. cannabis/

35. 33 or 34

36. 11 or 32

37.35 and 36

38. randomized controlled trial.pt.

39. controlled clinical trial.pt.

40. randomized.ab.

41. placebo.ab. 
Table 1. Search strategies and hits returned (Continued)

42. drug therapy.fs.

43. randomly.ab.

44. trial.ab.

45. groups.ab.

46. 38 or 39 or 40 or 41 or 42 or 43 or 44 or 45

47. humans.sh.

48.46 and 47

49. 37 and 48

50. HIV*.ti.

51.49 not 50

52. AIDS.ti.

53.51 not 52

54. stroke.ti.

55.53 not 54

56. diabet ${ }^{\star}$. ti.

57.55 not 56

58. heart.ti.

59.57 not 58

60. epilep*.ti.

61.59 not 60

62. schizophre*.ti.

63. 61 not 62

64. child ${ }^{\star}$. ti.

65.63 not 64

2. exp "senile dementia"/

3. "alzheimer disease"/

4. "diffuse lewy body disease"/

5. "frontotemporal dementia"/

6. "huntington chorea"/

7. "mental deterioration"/

8. "multiinfarct dementia"/

9. "pick presenile dementia"/

10. "presenile dementia"/ 
Table 1. Search strategies and hits returned (Continued)

11. exp "cognitive defect"/

12. "wernicke korsakoff syndrome"/

13. "korsakoff psychosis"/

14. "binswanger encephalopathy"/

15. "progressive supranuclear palsy"/

16. "organic brain syndrome"/

17.1 or 2 or 3 or 4 or 5 or 6 or 7 or 8 or 9 or 10 or 11 or 12 or 13 or 14 or 15 or 16

18. (dement $^{\star}$ or neuroprotect $\left.{ }^{\star}\right) \cdot \mathrm{mp}$.

19. alzheimer*.mp.

20. $\left(\right.$ lewy $^{\star}$ and bod $\left.{ }^{\star}\right) \cdot \mathrm{mp}$.

21. ((cognit* or memory ${ }^{\star}$ or mental $\left.{ }^{\star}\right)$ and $\left(\right.$ declin $^{\star}$ or impair ${ }^{\star}$ or $\operatorname{los}^{\star}$ or deteriorat $\left.\left.{ }^{\star}\right)\right)$.mp.

22. (chronic and cerebrovascular).mp.

23. ("organic brain syndrome" or "organic brain disease").mp. [mp=title, abstract, subject headings, heading word, drug trade name, original title, device manufacturer, drug manufacturer name]

24. "supra nuclear palsy".mp.

25. ("normal pressure hydrocephalus" and shunt ${ }^{\star}$.mp. [mp=title, abstract, subject headings, heading word, drug trade name, original title, device manufacturer, drug manufacturer name]

26. "benign senescent forgetfulness".mp.

27. (cerebr ${ }^{\star}$ and deteriorat ${ }^{\star}$ ).mp. [mp=title, abstract, subject headings, heading word, drug trade name, original title, device manufacturer, drug manufacturer name]

28. (cerebr* and insufficien*).mp. [mp=title, abstract, subject headings, heading word, drug trade name, original title, device manufacturer, drug manufacturer name]

29. (confusion* or confused).mp. [mp=title, abstract, subject headings, heading word, drug trade name, original title, device manufacturer, drug manufacturer name]

30. "pick's disease".tw.

31. (creutzfeldt or JCD or CJD).tw.

32. huntington ${ }^{\star} . t w$.

33. binswanger ${ }^{\star} . t w$.

34. korsako*.tw.

35. (wernicke* and syndrome).tw.

36. 18 or 19 or 20 or 21 or 22 or 23 or 24 or 25 or 26 or 27 or 28 or 29 or 30 or 31 or 32 or 33 or 34 or 35

37.17 or 36

38. randomized controlled trial/

39. randomization/

40. random*.mp. 
Table 1. Search strategies and hits returned (Continued)

41. controlled study/

42. clinical trial/ or phase 2 clinical trial/ or phase 3 clinical trial/ or phase 4 clinical trial/ or controlled clinical trial/

43. (cross-over or cross over or crossover).mp.

44. double blind procedure/

45. single blind procedure/ or triple blind procedure/

46. latin square design/

47. parallel design/

48. placebo/

49. placebo $^{\star} . \mathrm{mp}$.

50. (controlled adj5 (trial\$ or stud\$)).tw.

51. (clinical\$ adj5 trial\$).tw.

52. ((multicentre or multicenter) adj5 (trial\$ or stud\$)).tw.

53. ((singl\$ or doubl\$ or tripl\$ or trebl\$) adj5 (blind\$ or mask\$)).tw.

54. "latin square".tw.

55.38 or 39 or 40 or 41 or 42 or 43 or 44 or 45 or 46 or 47 or 48 or 49 or 50 or 51 or 52 or 53 or 54

56. human/

57. nonhuman/

58.56 and 57

59.57 not 58

60.55 not 59

61.37 and 60

62. HIV*.ti.

63.61 not 62

64. stroke.ti.

65.63 not 64

66. diabet ${ }^{*}$.ti.

67.65 not 66

68. heart.ti.

69.67 not 68

70. epilep*.ti.

71.69 not 70

72. schizo*.ti.

73. 71 not 72 
Table 1. Search strategies and hits returned (Continued)

74. child*.ti.

75.73 not 74

76. (cannabis or cannabinoid* or endocannabinoid* or cannbidiol or dronabinol or the or cbd or marihuana or marijuana or hashish).tw.

77. cannabis.sh.

78. 76 or 77

79. 75 and 78

Psyclnfo (Ovid SP) 1. exp presenile dementia/

2. exp senile dementia/

3. exp vascular dementia/

4. alzheimers disease/

5. (dement ${ }^{\star}$ or neuroprotect $\left.{ }^{\star}\right) \cdot \mathrm{mp}$.

6. alzheimer ${ }^{\star} . \mathrm{mp}$.

7. ("randomi?ed controlled trial" or "clinical controlled trial").mp.

8. (random* or placebo*).mp.

9. (cannabis or cannabinoid ${ }^{\star}$ or endocannabinoid ${ }^{\star}$ or cannabidiol or dronabinol or the or cbd or marihuana or marijuana or hashish).mp.

10. cannabis.sh.

11. 1 or 2 or 3 or 4 or 5 or 6

12. 7 or 8

13. 9 or 10

14. 11 and 12 and 13

15. limit 14 to $y r=" 2006-2008 "$

Cinahl (Ovid SP)

1. exp dementia presenile/

2. exp dementia senile/

3. exp dementia multi infarct/

4. exp huntington's disease/

5. 1 or 2 or 3 or 4

6. $\left(\right.$ dement $^{\star}$ or neuroprotect $\left.{ }^{\star}\right) \cdot \mathrm{mp}$.

7. alzheimer ${ }^{\star} . \mathrm{mp}$.

8. (lewy* and bod $\left.{ }^{\star}\right) \cdot m p$.

9. ((cognit ${ }^{\star}$ or memory ${ }^{\star}$ or mental $\left.{ }^{\star}\right)$ and (declin* or impair $^{\star}$ or los ${ }^{\star}$ or deteriorat $\left.\left.{ }^{\star}\right)\right)$.mp.

10. (chronic and cerebrovascular).mp.

11. ("organic brain syndrome" or "organic brain disease").mp.

12. "supra nuclear palsy".mp. 
Table 1. Search strategies and hits returned (Continued)

13. ("normal pressure hydrocephalus" and shunt $\left.{ }^{\star}\right) . \mathrm{mp}$.

14. $\left(\right.$ cerebr $^{\star}$ and deteriorat $\left.{ }^{\star}\right) \cdot \mathrm{mp}$.

15. (cerebr ${ }^{\star}$ and insufficien $\left.{ }^{\star}\right) \cdot \mathrm{mp}$.

16. (confusion* or confused).mp.

17. "pick's disease".mp.

18. (creutzfeldt or JCD or CJD).mp.

19. Huntington ${ }^{\star} . m p$.

20. binswanger ${ }^{\star} \cdot \mathrm{mp}$.

21. korsako*.mp.

22. (wernicke* and syndrome).mp.

23. 6 or 7 or 8 or 9 or 10 or 11 or 12 or 13 or 14 or 15 or 16 or 17 or 18 or 19 or 20 or 21 or 22

\section{5 or 23}

25. randomized controlled trial.mp.

26. random*.mp.

27. placebo*.mp.

28. (control ${ }^{\star}$ or prospective ${ }^{\star}$ or volunteer $\left.{ }^{\star}\right) \cdot \mathrm{mp}$.

29. ((singl ${ }^{\star}$ or doubl* or trebl ${ }^{\star}$ or tripl $\left.l^{\star}\right)$ and $\left(\right.$ blind $^{\star}$ or mask $\left.\left.^{\star}\right)\right)$.mp.

30. (cross-over ${ }^{\star}$ or crossover $\left.{ }^{\star}\right) \cdot \mathrm{mp}$.

31.25 or 26 or 27 or 28 or 29 or 30

32. 24 and 31

33. (cannabis or cannabinoid* or endocannabinoid* or cannabidiol or dronabinol or the or cbd or marihuana or marijuana or hashish).mp.

34. cannabis.sh.

35.33 or 34

36. 32 and 35

The Cochrane Li- (cannabis or cannabinoid* or endocannabinoid* or marijuana or hashish) [searched as lar dementia OR vascular cognitive impairment OR multi-infarct OR (lewy ${ }^{\star}$ AND bod ${ }^{\star}$ ) OR delir* OR (dementia Alzheimer type/) OR (dementia vascular/))

[searched as title, abstract, keyword, controlled vocabulary]

\begin{tabular}{ll}
\hline LILACs (Bireme) & (cannabis or cannabinoid\$ or endocannabinoid\$ or marijuana or hashish) AND ((de- \\
& ment\$ OR (vascular dementia) OR (vascular cognitive impairment) OR (multi-infarct) OR \\
& alzheimer\$))
\end{tabular}

\begin{tabular}{ll}
\hline African Index & (estud\$ or clin\$ or grupo $\$$ or comparative study or placebo $\$$ or random\$) AND (cannabis \\
Medicus & or cannabinoid\$ or endocannabinoid\$ or marijuana or hashish)
\end{tabular}
0 
Table 1. Search strategies and hits returned (Continued)

\begin{tabular}{ll} 
Korea Med & cannabis or cannabinoid\$ or endocannabinoid\$ or marijuana or hashish \\
\hline $\begin{array}{l}\text { Thompson Scien- } \\
\text { tific }\end{array}$ & cannabis or cannabinoid or endocannabinoid or marijuana or hashish) AND dementia \\
\hline $\begin{array}{l}\text { Allied and Com- } \\
\text { plementary Medi- } \\
\text { cine Database }\end{array}$ & cannabis or cannabinoid\$ or endocannabinoid\$ or marijuana or hashish \\
\hline $\begin{array}{l}\text { ClinicalTrials.gov } \\
\text { (cannabis OR cannabinoid) AND (dementia OR Alzheimer) }\end{array}$ & 2 \\
\hline $\begin{array}{l}\text { Meta Register } \\
\text { for Current Con- } \\
\text { trolled Trials }\end{array}$ & (cannabis OR cannabinoid OR marijuana OR hashish) AND (dementia OR Alzheimer) \\
\hline
\end{tabular}

\begin{tabular}{ll}
\hline $\begin{array}{l}\text { Meta Register } \\
\text { for Current Con- }\end{array}$ & (cannabis OR cannabinoid OR marijuana OR hashish) AND (dementia OR \\
$\begin{array}{l}\text { trolled Trials - } \\
\text { archive }\end{array}$ & Alzheimer)
\end{tabular}

\begin{tabular}{|c|c|c|}
\hline $\begin{array}{l}\text { European Medi- } \\
\text { cines Agency }\end{array}$ & (cannabis OR cannabinoid) AND (dementia OR Alzheimer) & 0 \\
\hline $\begin{array}{l}\text { World Health Or- } \\
\text { ganizations Trials } \\
\text { Platform }\end{array}$ & $\begin{array}{l}\text { (cannab* AND dement*) OR (cannab* AND Alzheimer*) OR (marijuana AND dementia) OR } \\
\text { (endocannabinoid }{ }^{\star} \text { AND dementia) }\end{array}$ & 0 \\
\hline $\begin{array}{l}\text { Hong Kong Clini- } \\
\text { cal Trials }\end{array}$ & $\begin{array}{l}\text { alzheimer* AND (cannabis OR cannabinoid* OR endocannabinoid* OR marijuana OR } \\
\text { hashish) }\end{array}$ & 0 \\
\hline $\begin{array}{l}\text { Clinical Trials Reg- } \\
\text { istry India }\end{array}$ & $\begin{array}{l}\text { (alzheimer* OR dement*) AND (cannabis OR cannabinoid* OR endocannabinoid* OR mar- } \\
\text { ijuana OR hashish) }\end{array}$ & 0 \\
\hline $\begin{array}{l}\text { IFPMA Clinical Tri- } \\
\text { als Portal }\end{array}$ & cannabis OR cannabinoid ${ }^{\star}$ OR endocannabinoid OR marijuana OR hashish & 26 \\
\hline ISRCTN & $\begin{array}{l}\text { (cannabis or cannabinoid* or endocannabinoid }{ }^{\star} \text { or marijuana or hashish) AND (dement } \\
\text { or alzheimer }{ }^{\star} \text { ) }\end{array}$ & 2 \\
\hline $\begin{array}{l}\text { Netherlands Trials } \\
\text { Register }\end{array}$ & cannabis or cannabinoid ${ }^{\star}$ or endocannabinoid ${ }^{\star}$ or marijuana or hashish & 0 \\
\hline $\begin{array}{l}\text { Umin Clinical Tri- } \\
\text { als Registry }\end{array}$ & $\begin{array}{l}\text { Searching on dementia on this register retrieves nothing. Cognition is the term that ap- } \\
\text { pears to have been used instead. }\end{array}$ & 0 \\
\hline $\begin{array}{l}\text { Google search en- } \\
\text { gine }\end{array}$ & (cannabis OR cannabinoid) AND (dementia OR Alzheimer's) & 222000 \\
\hline Norml website & dementia OR Alzheimer & 76 \\
\hline
\end{tabular}

\section{CONTRIBUTIONS OF AUTHORS}

SK: draft protocol and review: select studies; assess study quality; extract data; data analysis; all correspondence RC: draft protocol and review: select studies; assess study quality; extract data; data analysis

$\mathrm{RH}$ : adjudicate over any disagreements about the inclusion and quality of studies and any disagreements regarding data extraction. 


\section{DECLARATIONS OF INTEREST}

None known.

\section{INDEX TERMS}

\section{Medical Subject Headings (MeSH)}

Alzheimer Disease [drug therapy]; Cannabinoids [adverse effects] [ ${ }^{\star}$ therapeutic use]; Dementia [ ${ }^{\star}$ drug therapy]; Dronabinol [adverse effects] [therapeutic use]; Psychotropic Drugs [adverse effects] [therapeutic use]

\section{MeSH check words}

Humans 